\title{
Social and Economic Difficulties Caused by Khat Usage in Somalia
}

\author{
Said Sheikh Aden Awale \\ Eagle Consultancy \\ Ali Yassin Sheikh Ali \\ Faculty of Economics \\ Simad University
}

\begin{abstract}
This Paper Examines the socio-economic consequences of khat usage in Somalia, covering khat usage and habits, willingness to quit, health outcomes, and types of khat used and from where it is imported. A total of 383 face-toface interviews were administered to males aged 18 and above from five districts in Mogadishu, the capital city of Somalia using a cross-sectional design. The study population was estimated to be 120,000 individuals (4\% of the population of Mogadishu).A systematic random sampling technique was employed to select khat chewers and cluster sampling also was used to select the participants. The districts chosen were highly populated areas that act as strategic highways for khat; many khat chewers and sellers live in these districts. The study employed SPSS to analyze the data. The primary benefits of taking khat were found to be excitement and a feeling of well-being (46\% and 41\%, respectively). The major negative effects were sleeping disorders (83\%), reduced appetite (50\%), depression (29\%), and anxiety (24\%). Most respondents realized the negative effects of chewing khat only when it was too late and they were already addicted. Almost everyone (92\%) wanted to stop chewing khat. The major reason for wanting to stop chewing khat was the negative health effects. On average, users chewed over $250 \mathrm{~g}$ of khat per day, spending an average of USD 7.29. Severalscholars have argued that if Somalia did not import khat, the country would be one of the most socio-economically developed countries in Africa. The country would save millions of dollars every day, people who work would contribute their full income to their families, and there would be greater impact on work performance in the areas that promote economic growth. The overall health of the nation would also be improved, further improving socio-economic conditions in Somalia. This study is, to our knowledge, the most detailed study of khat usage in Somalia to date. Several recommendations are made regarding how to effectively reduce both khat usage and the buying and selling of khat.
\end{abstract}

Keywords: Khat, Addiction, Socio-economic effects, Health, Somalia

\section{Introduction}

Khat is a plant with stimulant properties that grows in many parts of the highlands in east Africa and some Arab countries. Traditionally, khat has been used for medical purposes, including: treating the symptoms of, and increasing resistance to, coughs, bronchial asthma, hay fever, fatigue, diabetes, and malaria; an appetite suppressant to aid weight loss; an aphrodisiac; and increasing levels of alertness, ability to concentrate, and confidence (Genene, Haniko \& Weldegerima2009). Khat leaves are cultivated in the highlands of the Horn of Africa, Southern Arabia, and along the East African coast (Alyi Mohamed, 2014). In parts of Ethiopia, Kenya, Somalia, and Yemen, khat leaves have been chewed for many centuries. Ethiopia is khat's country of origin (the khat-chewing habit began in approximately the fifteenth century) and it is currently the world's largest khat producer. Khat has many names indifferent countries, including "qat" (Yemen), "jad" or "chad" (Ethiopia, Somalia), "miraa" (Kenya), and "marungi" (Uganda and Rwanda).

Most European countries have prohibited the chewing and consumption of khat, but it is still widely used in several diaspora communities those living in UK (Anderson \& Carrier, 2011) where khatis considered an illegal drug but it is consumed by many in Ethiopian, Somali, Kenyan, and Yemen immigrant communities. Khat consumption leads to corruption and other criminal practices because the habit is quite costly (considering the per capita income) and the consumer is compelled to earn more money to satisfy his/her habit by whatever means necessary. Social injustice and miss-administration arise from this and will continue to increase if this phenomenon continues to proliferate; society and the economy will suffer. 
Khat consumption has been demonstrated to lead to family instability and household poverty, irritability in users and a reduction in men's sexual activity. These factors may lead to family breakup, loss of working hours, and negative effects on children's lives in many aspects (Panteliset al., 1989). Many Somali scholars have argued that if Somalia did not import khat, the country would be one of the most socially and economically developed countries in Africa. The country would save millions of dollars every day, the people who work would contribute their full income to their families, and there would be a significant impact on work performance in is as that promotes economic growth. Families and couples would be more stable, fathers would be more aware of their children and how they are performing in education. The overall health of the nation would also be improved, further improving socio-economic conditions in Somalia.

Currently, khat is chewed worldwide and Somalia is one of the countries with the highest proportion of khat users. The practice of chewing khat ("jaad" or "qaad") started at different times in the different parts of Somalia. Notably, $80 \%$ of khat users are estimated to be less under35 years of age (Nabuzoka and Badhadhe, 2000).

\section{Literature review}

A series of recent studies has indicated that the khat habit has spread in last two decades spreads into Europe and North America from East African and some Arab countries. According to a study by Aden et al. (2006) examining the socio-economic effects of khat chewing in the Ijara district, the khat habit negatively impacted family relationships and health and increased anti-social behavior; the majority of khat users had children. Many of these chewers had begun to use khat during the day to increase their work productivity but, unfortunately, $40 \%$ of them saw a decrease in their work performance (Adenet al., 2006).

Similarly, Kassim et al. (2013) proved, in the UK, that khat chewing was similar in many ways to nicotine use: the objective of their study was to assess dependency syndrome forkhat chewing and to examine the psychological, financial, and behavioral factors related to this drug habit and other drugs, such as tobacco. Sheikh et al. (2014) emphasized that khat chewing is associated with lower quality of life and increased chance of death, especially for those who consume khat daily over long periods. The aim of this study was to measure and compare the quality of life of khat chewers and non-khat chewers and to assess factors associated with khat chewing. Prior research has also suggested that khat chewing is associated with elevated diastolic blood pressure, consistent with peripheral vasoconstriction by cathinone, which has a negative impact on health. For several years, significant effort has been devoted to the study of the economic and social effects of khat chewing. Some countries, however, believe that khat plays an important role in the national economy as a major export.

As according to Megerssa (2013), "Miraa" - a controversial crop in Ethiopia - contributes to approximately $13.4 \%$ of the national income. This study, which aimed to identify both beneficial and harmful socioeconomic effects of khat use, asserted that the psychoactive action has adverse socio-economic and health effects. Extensive literature over many years investigating the significant relationship between khat and its economic, political and socioculture effects on the people of Somaliland people has provided conflicting results and opinions. Hansen (2010), for example, employed joint needs assessmentover13months for people in Somaliland and Somalis in London. The results of the study showed that khat use created work opportunities for many people and increased their income and that khat was a benefit to the government, both in terms of increased revenue and political stability. The likelihood of khat consumption was also increased by factors associated with socio-cultural changes following number wars in Somali land in the twentieth century (Hansen, 2010).

Khat is, in summary, a crop strongly linked to economic, religious, educational, and socio-cultural issues; it creates, however, conflicts and confusion among khatfarmers and traders who are dependent on khat consumption and has a negative and dangerous effect on school child, families, and the whole of the society.

\section{Methodology}

A total of 383 face-to-face interviews were administered to males aged 18 and above from five districts in Mogadishu (Hodan, Wadajir, Hamarweyne, Hawlwadaag, and Waabari), the capital city of Somalia using a crosssectional design. The study population was estimated to be 120,000 individuals (4\% of the population of Mogadishu). For data collection, a systematic random sampling technique was employed to select khat chewers and cluster sampling also was used to select the participants of the study. The sample size $(n)$ of the study was calculated to by considering $95 \%$ confidence level $(p=0.5$; margin error $(d) 5 \%=(0.05))$. The districts chosen are highly populated areas, located at strategic highways, and many khat chewers and sellers live in these districts. 
The objectives of this study were developed based on the socio-economic difficulties caused by khat usage in Somalia. The study employed SPSS as instrument for analyzing data.

\section{Data analysis and Findings}

\section{Demographics}

The demographic information regarding the age and marital status of the respondents is presented in Figure 1.The largest group of respondents (23\%) were aged 36-40 and 76\% of respondents were married.

Figure 1. Age and marital status of participants .

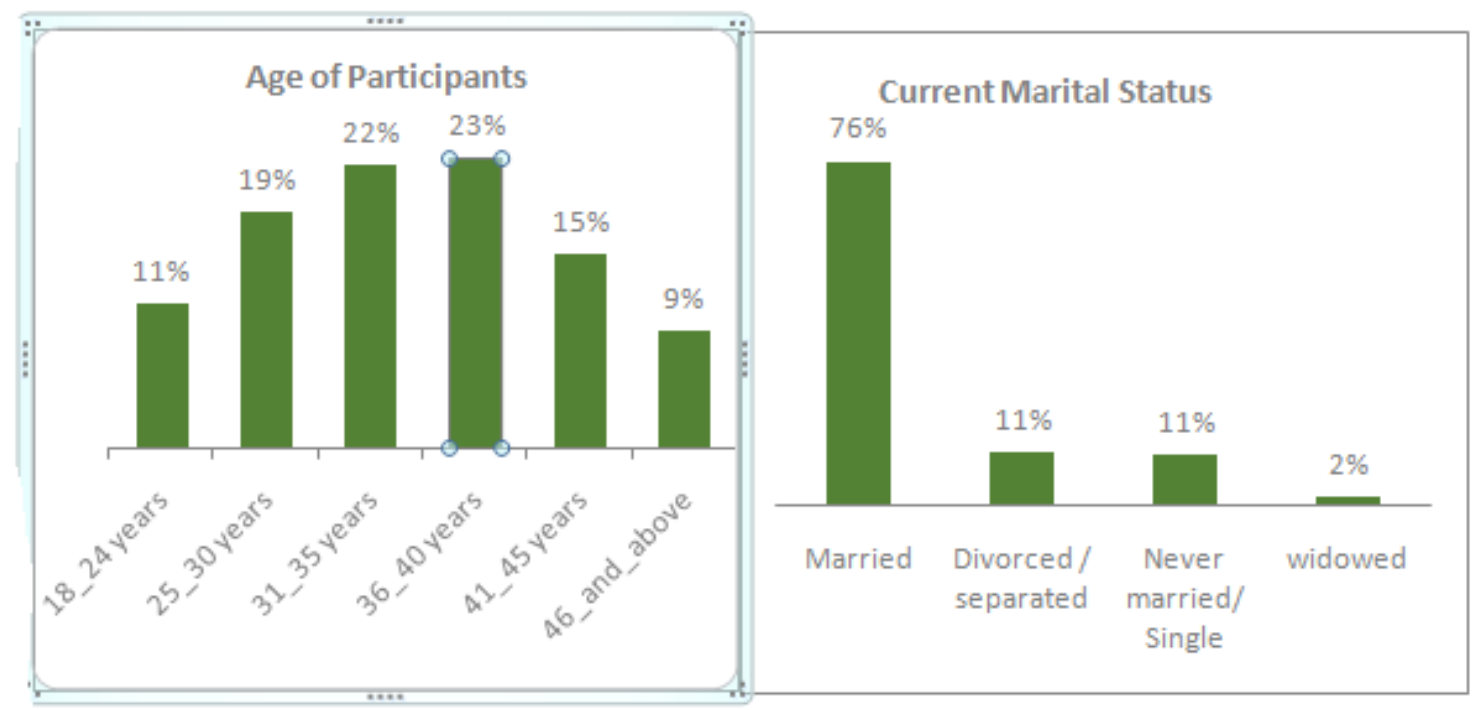

Figure 2 highlights the generally low level of educational attainment of the respondents. A total of $49 \%$ had completed only holy kur'an karim education from the Madarassa Koran and 12\% had no formal education (3\% refused to provide any information about their educational background). A total of $23 \%$ of the respondents had completed only primary education before starting khat chewing, $13 \%$ had completed secondary education.

Figure 2. Level of education.

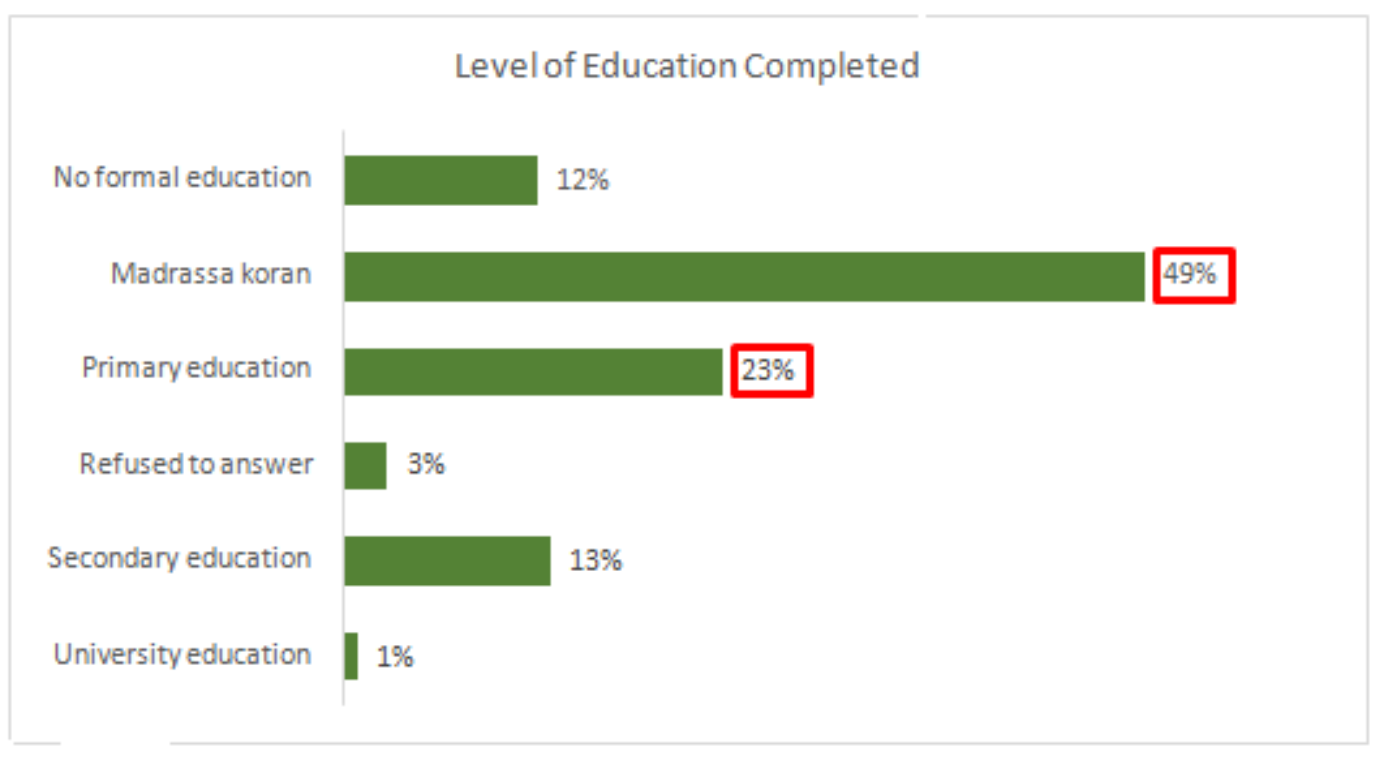


Figure 3 highlights the reasons why respondents had family members under the age of 18 not in formal education (24\% of the sample). The primary reasons were the lack of school fees $(91 \%)$ and the lack of a school uniform (36\%).Security issues, household chores, and working to bring income into the household accounted for $4 \%, 3 \%$, and $3 \%$, respectively.

Figure 3. Persons less than 18 years of age in the household not attending school

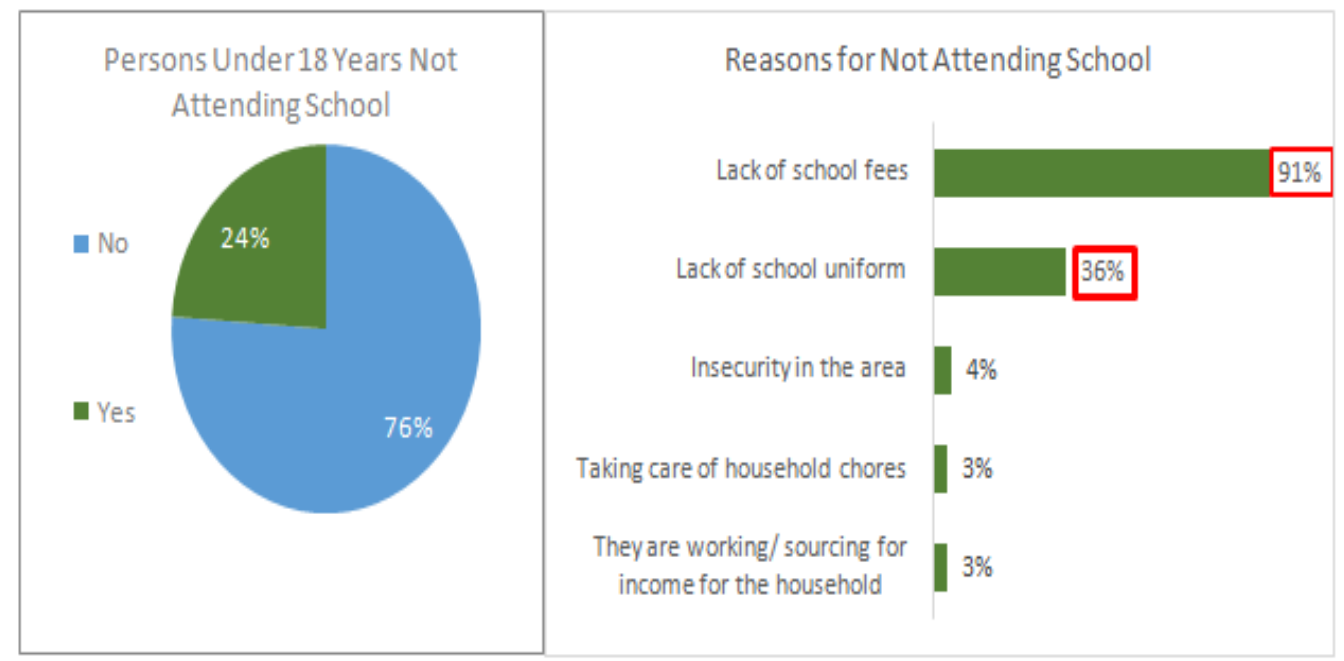

Regarding the source of income of khat users (see Figure 4), by far the largest group (40\%) was unskilled laborers. The "handicrafts" group (22\%) covers low-skilled jobs such as harvesting. However, $5 \%$ of khat users were skilled laborers. The remaining khat users generated their income from sources including remittances, government aid, small trading, selling charcoal, fishing, and financial help from relatives.

Figure 4. Source of income.

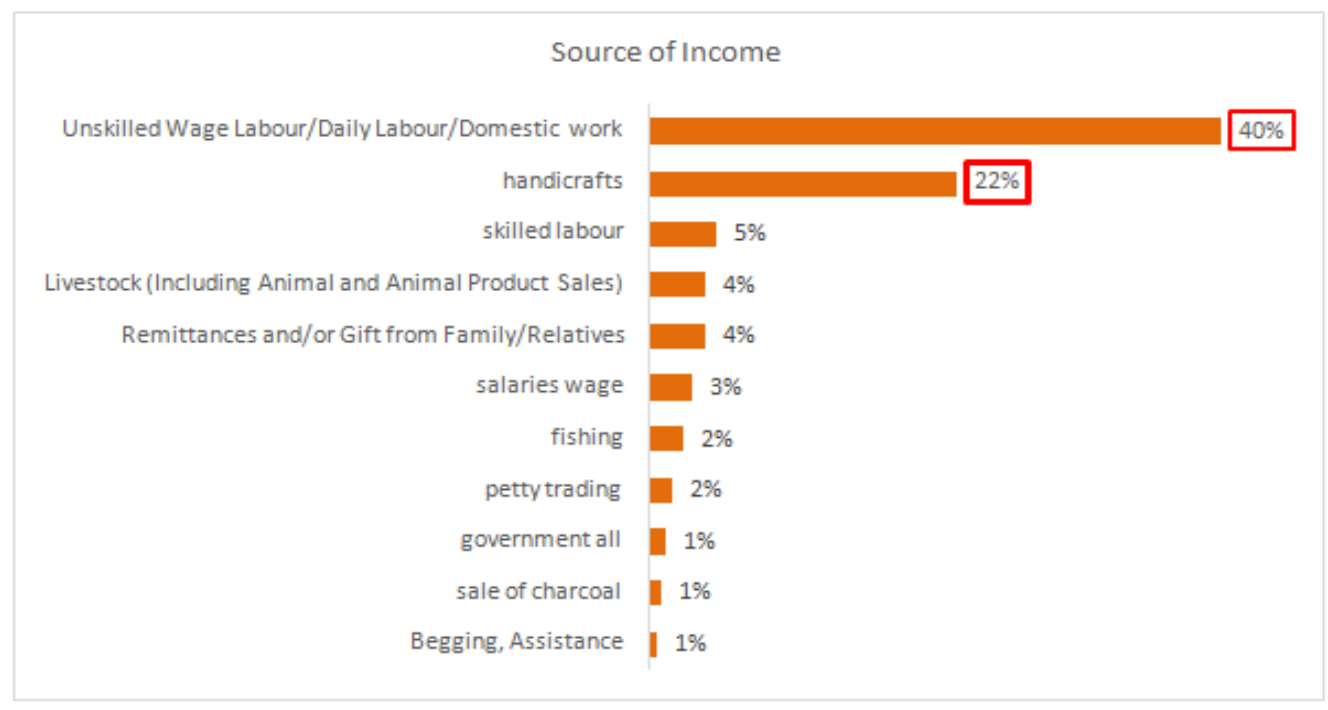

The majority (51\%) of respondents fell within the monthly income band of USD 150 to 250 (see Table I), with27\% earning above USD 250 and 24\% earning less than USD 150. One must presume that, if the time spentusing khat were fully and positively utilized, then these figures for income would increase, leading to various positive social outcomes, as will be discussed later. 
Table I.Monthly income (USD).

\begin{tabular}{|l|l|}
\hline \multicolumn{2}{|l|}{ Monthy Income } \\
\hline below 50 & $3 \%$ \\
\hline 50 to 100 & $8 \%$ \\
\hline 100 to 150 & $13 \%$ \\
\hline 150 to 200 & $27 \%$ \\
\hline 200 to 250 & $24 \%$ \\
\hline 250 to 300 & $14 \%$ \\
\hline 300 to 400 & $6 \%$ \\
\hline 400 to 500 & $2 \%$ \\
\hline more than 500 & $2 \%$ \\
\hline
\end{tabular}

\section{Patterns of khat usage}

All the respondents interviewed in this study chewed Khat and majority of them (67\%) reported that they initially started chewing khat through their close friends, $28 \%$ started on their own, and only $4 \%$ were initiated by family members (see Figure 5). Thus, peer pressure is the major contributor and determinant of khat usage. Therefore, it would be beneficial to formulate ways of more effectively engaging the community, especially men, who make upthe majority of khat users, as discussed later.

Figure 5.Initiatorsof respondents' khat chewing.

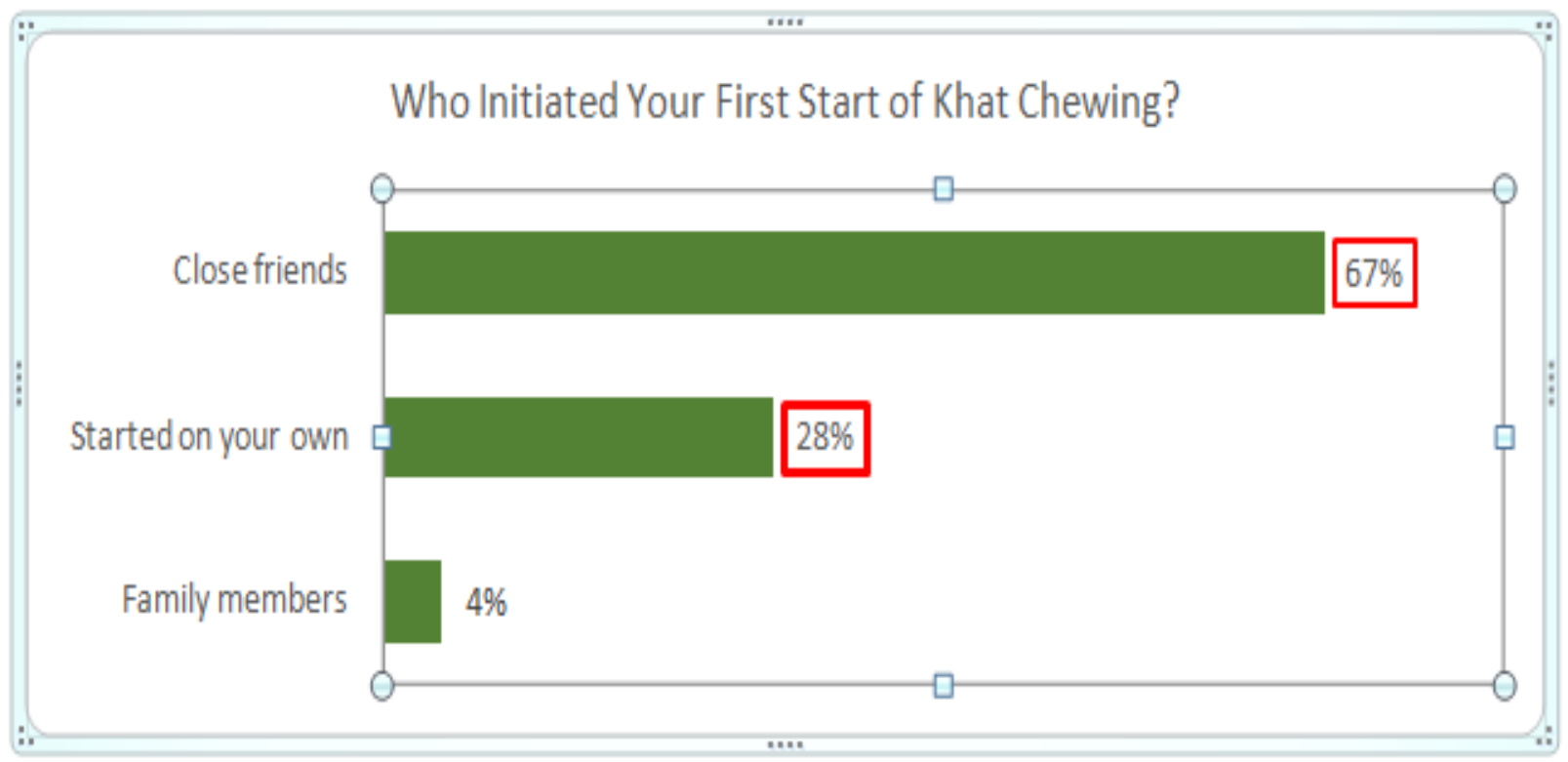

A total of $39 \%$ of respondents reported being the only khat userin their household (see Figure 6). The majority (61\%), however, reported that others in the home also used khat. This insight is particularly worrying; it highlights the need for effective means of reducing or eradicating the use of khat (we also know that khat usage in Somalia is generally very high).Figure 7 provides details of how many other users there were in the home, with the largest group being one other user (37\%). 
Figure 6. Whether others in the household chew khat.

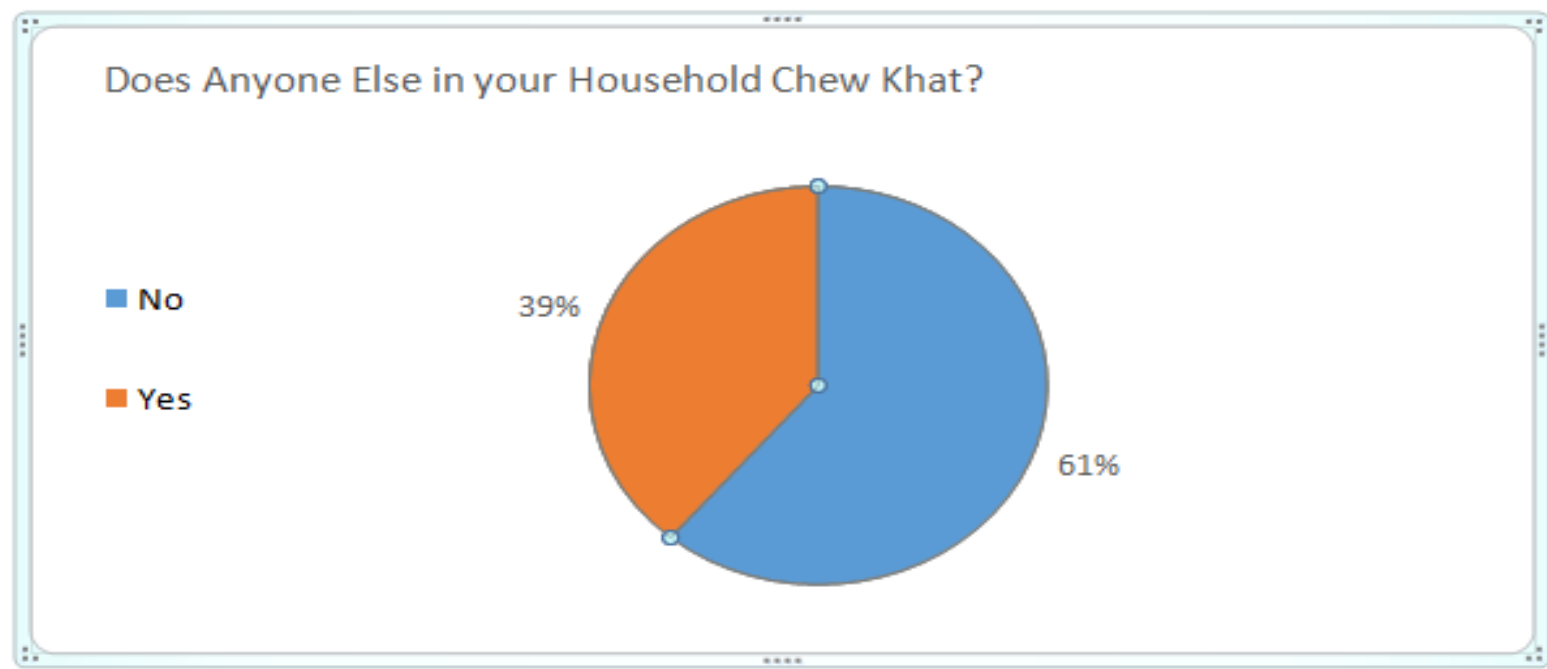

<FIG 7 HERE>

The study found khat usage was usually a long-term behavior. As shown in Figure 8,94\% of the respondents had used khat for more than three years. This further demonstrates the need to formulate ways of engaging with the community to reduce or eradicate khat usage.

Figure 7.How many others in the household chew khat.

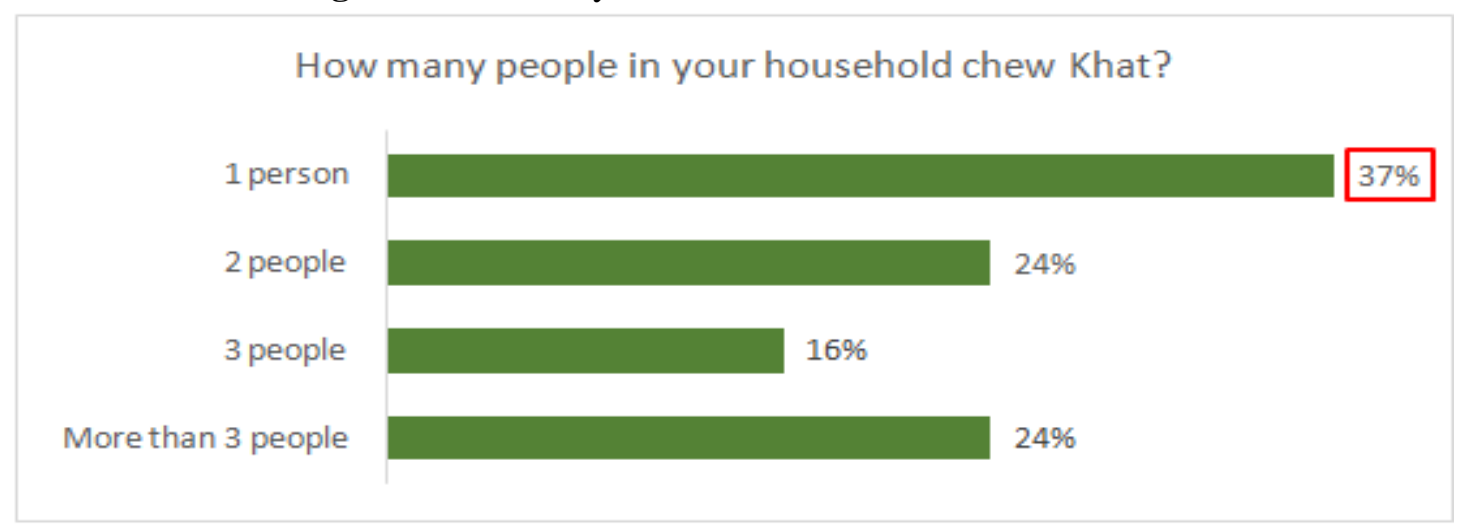

Figure 8.Number of yearschewing khat.

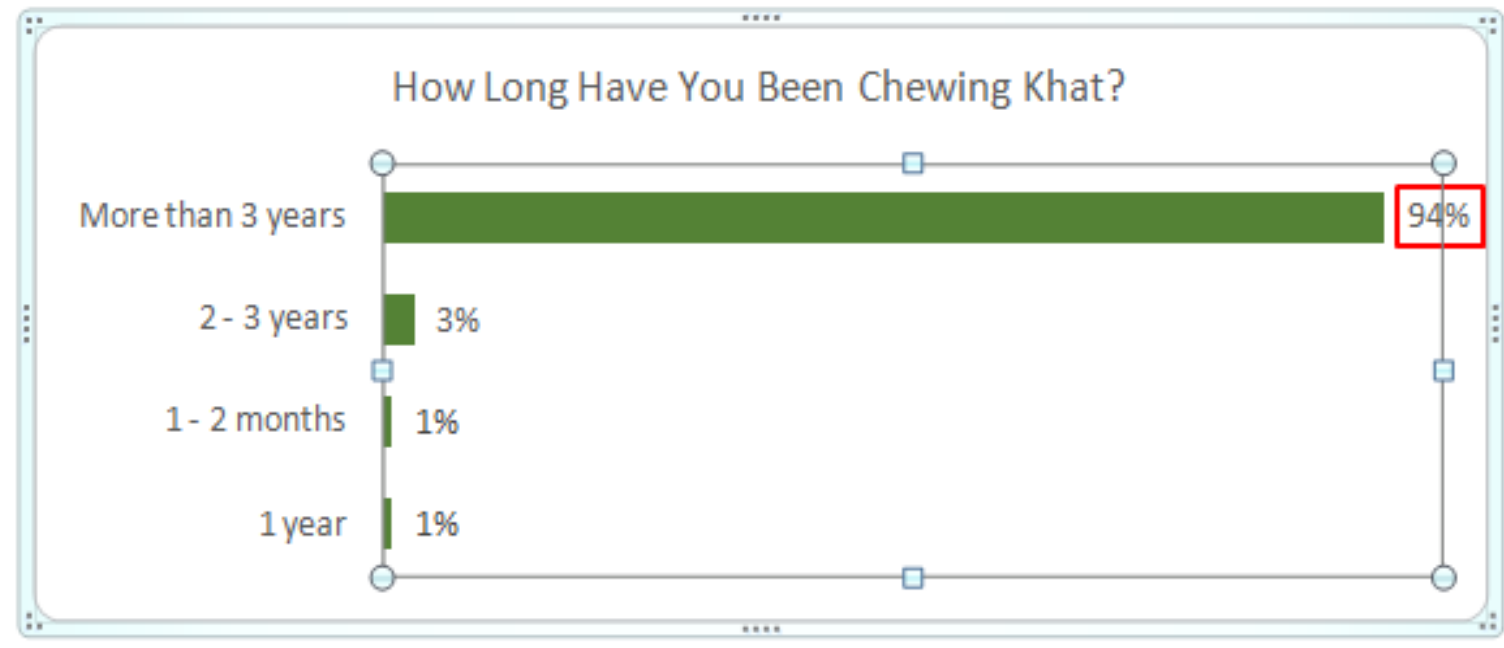

Figure 9 reveals that almost all factors examined contributed to the use of khat:excitement (44\%); a feeling of well-being (39\%); and to help pass the time (31\%). Notably, only $1 \%$ reported that they use khat because it is part of their culture. 
Figure 9. Reason for taking khat.

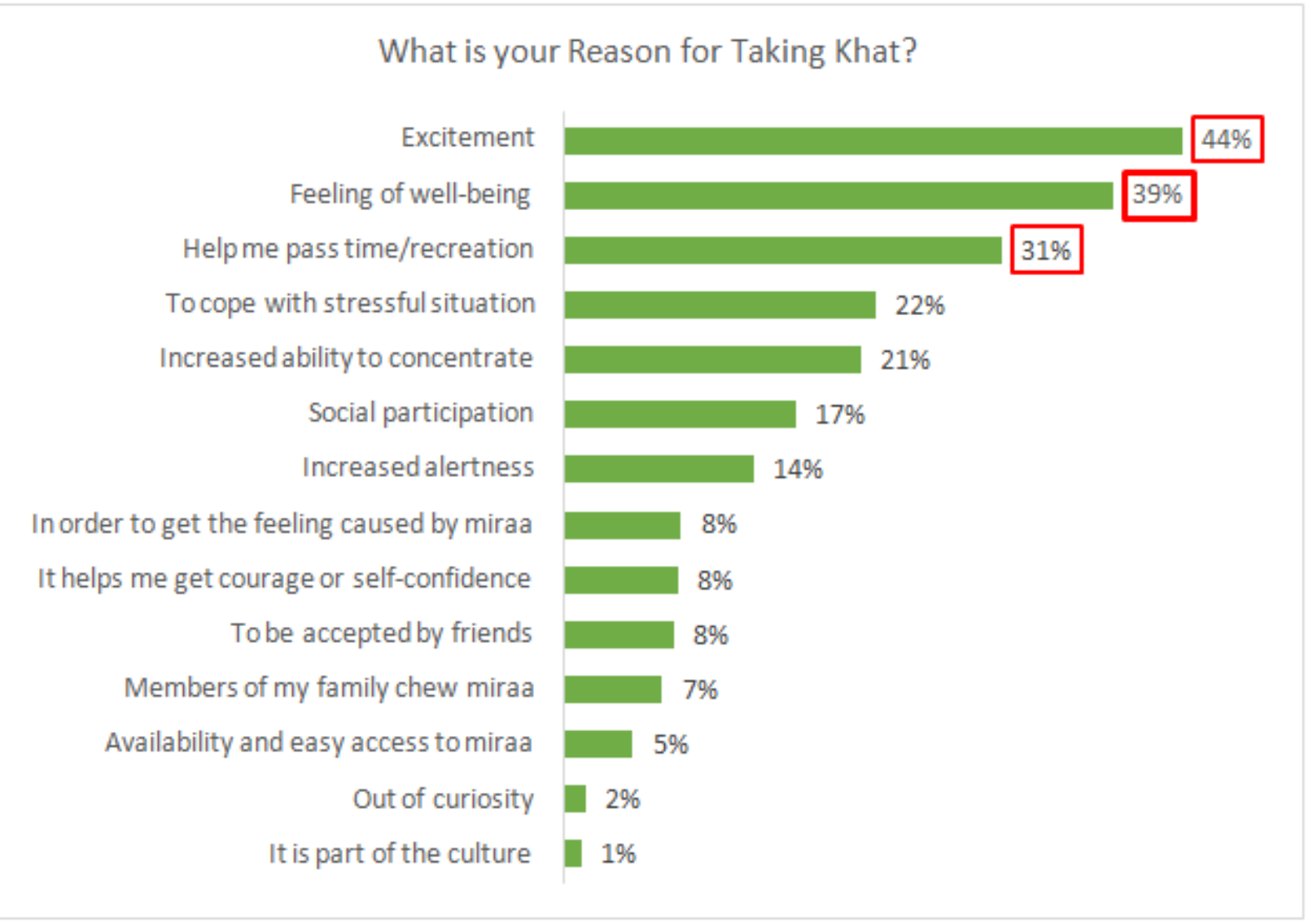

According to the data regarding the frequency of khat usage, the most common frequency is once a day (54\%), followed by two to three times a week (18\%) (see Figure 10). A total of $98 \%$ of the respondents used khat at least very week and $90 \%$ consumed hat more than once per week. Respondents mostly preferred to chew khat in the afternoon and evening (92\%); this information can be usedto develop strategies to reduce khat usage by targeting and providing alternative activities around the times of most frequent usage.

Figure 10. Frequency of chewing khat and time of day preferred.

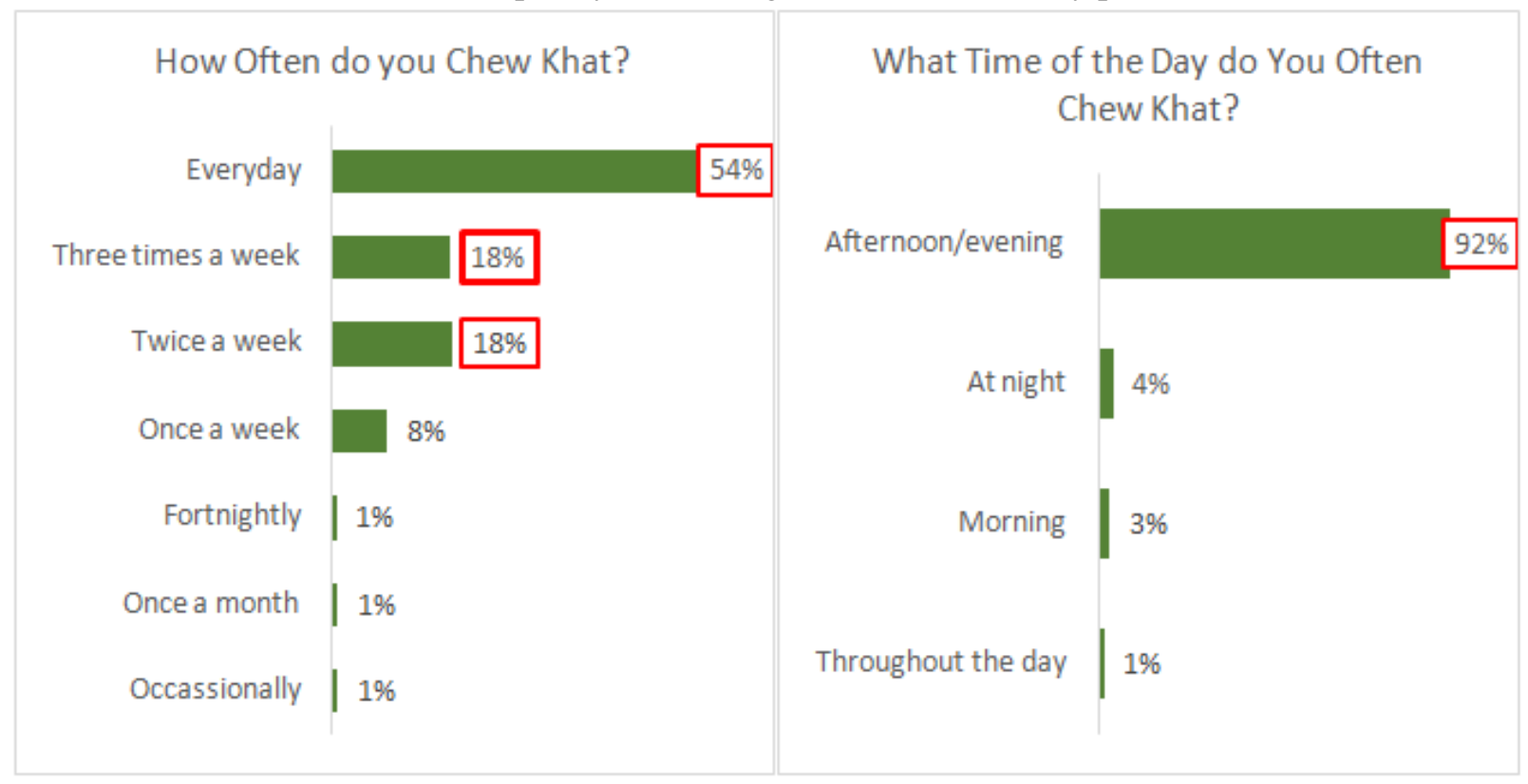




\section{Availability of khat}

The findings confirm that Kenya is the main grower and exporter of Khat to Somalia. A total of $99 \%$ of the respondents confirmed that thekhat they used was mainly grown in Kenya (see Figure 11). The most popular types of Khat were: Lary (96\%); Gise (65\%); Kabaje (54\%); Gangeyte (50\%); and Jaadbiid (31\%) (see Figure $12)$.

Figure 11. Origins ofkhat used.

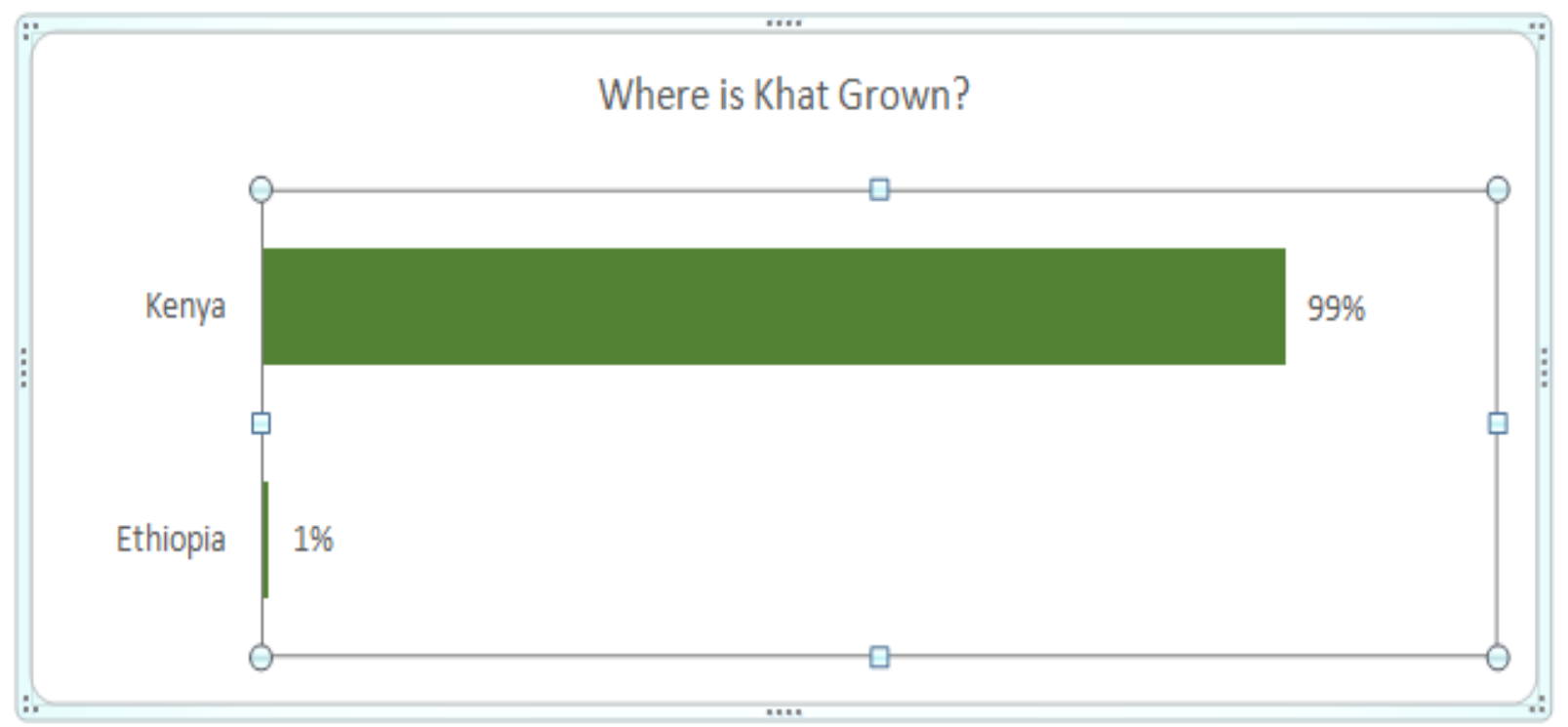

Figure12. Types of khat respondents were aware of.

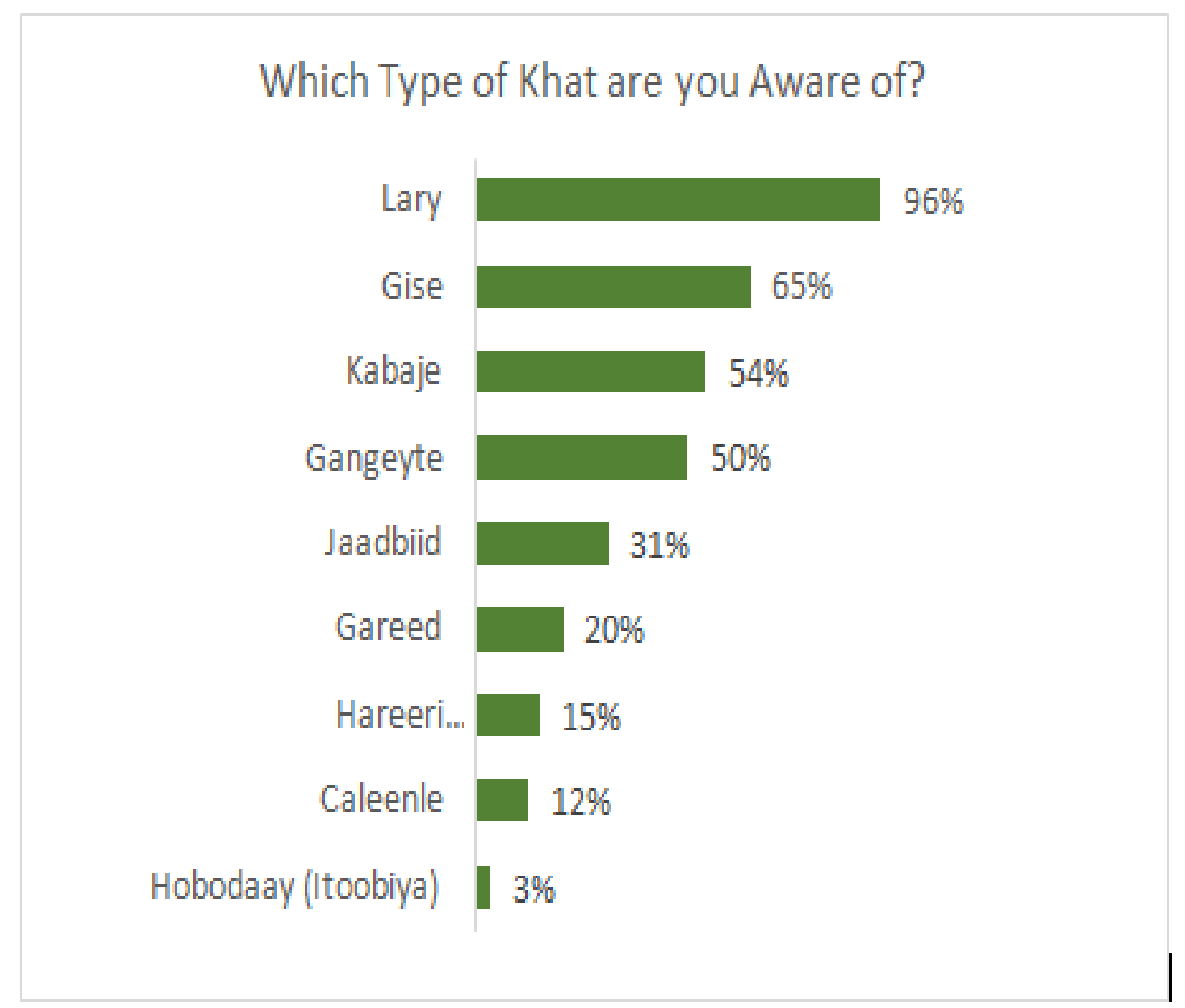

A total of $54 \%$ of respondents reported buying khat from the khat market and $46 \%$ reported that they purchased khat from the streets vendors (see Figure 13). Selling khat is a business that generates income for the owners of those businesses; therefore, these sellers must be encouraged to sell useful and healthy things rather thankhat, as will be discussed later. 
Figure 13. Wherekhat was bought.

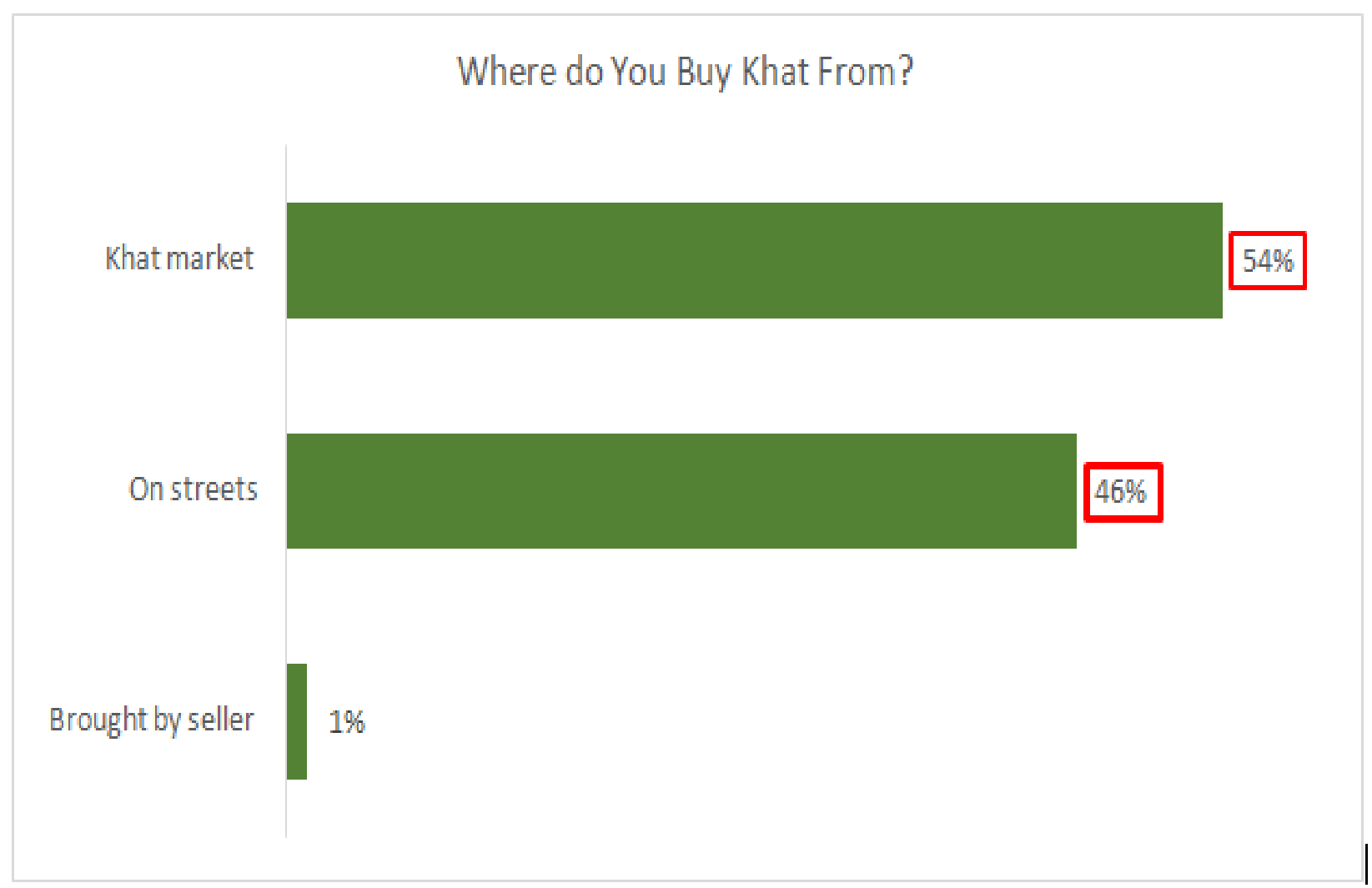

The ease of access to khat is clearly, however, an issue. Khat bundles, vendors, and even the markets are very close to the majority of consumers. A total of $62 \%$ of respondents reported that the distance was $0.5 \mathrm{~km}$ or less (Figure 14) and it took $71 \%$ of respondents 15 minutes or less to the reach the place where they bought their khat (Figure 15), with $70 \%$ of respondents travelling by foot (Figure 16).

Figure14. Distance from nearest place that sells khat.

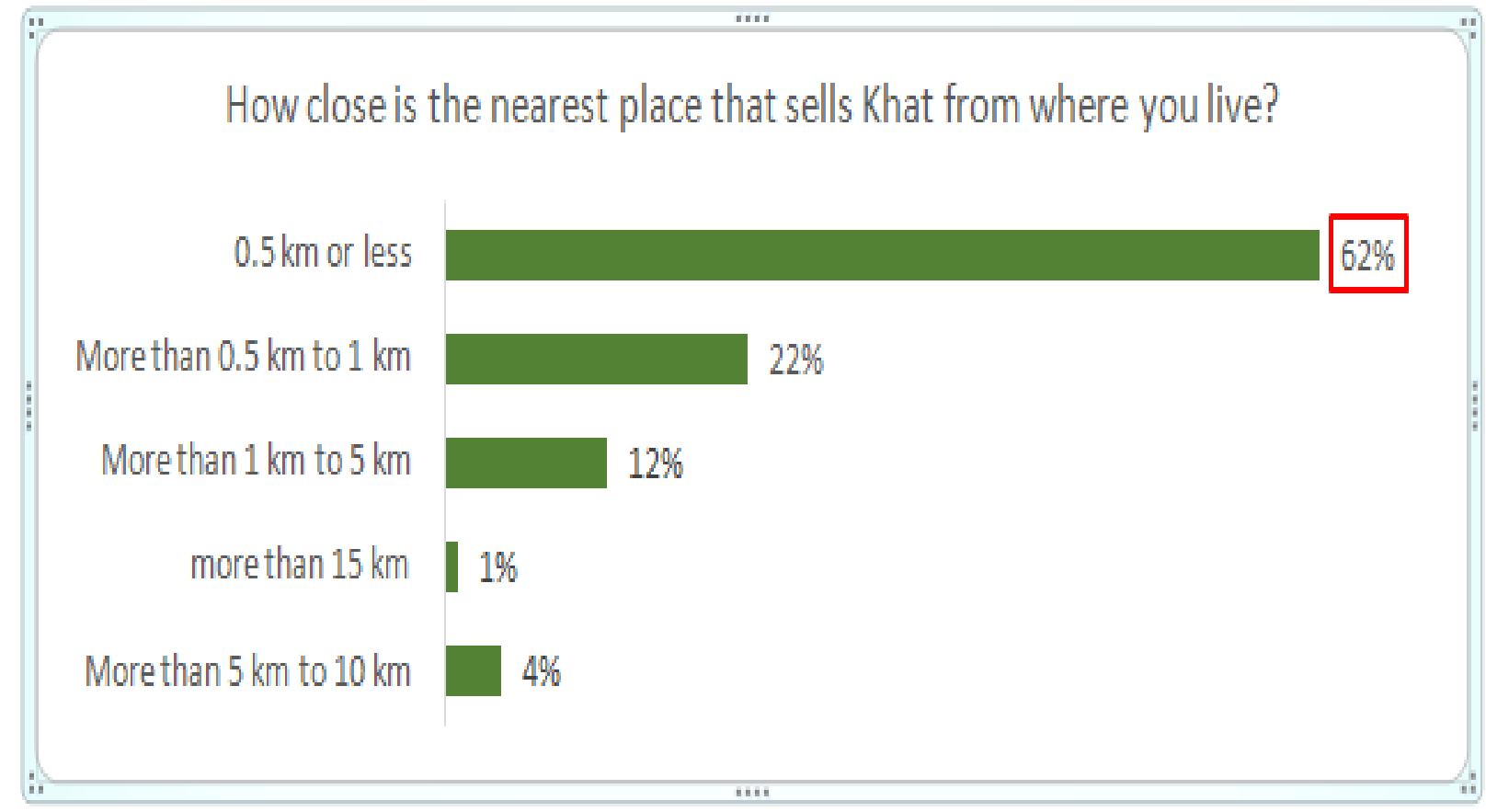


Figure 15. Time needed to travel to the nearest place that sells khat.

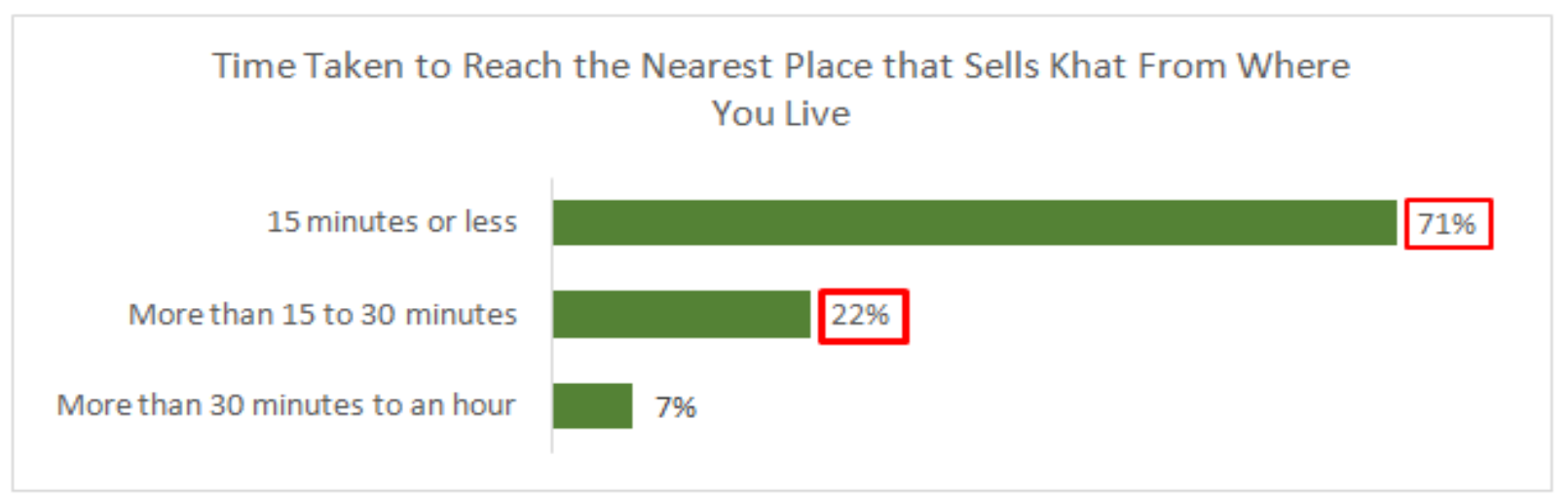

Figure16.Usual modes of transport to reach the nearest place that sells khat.

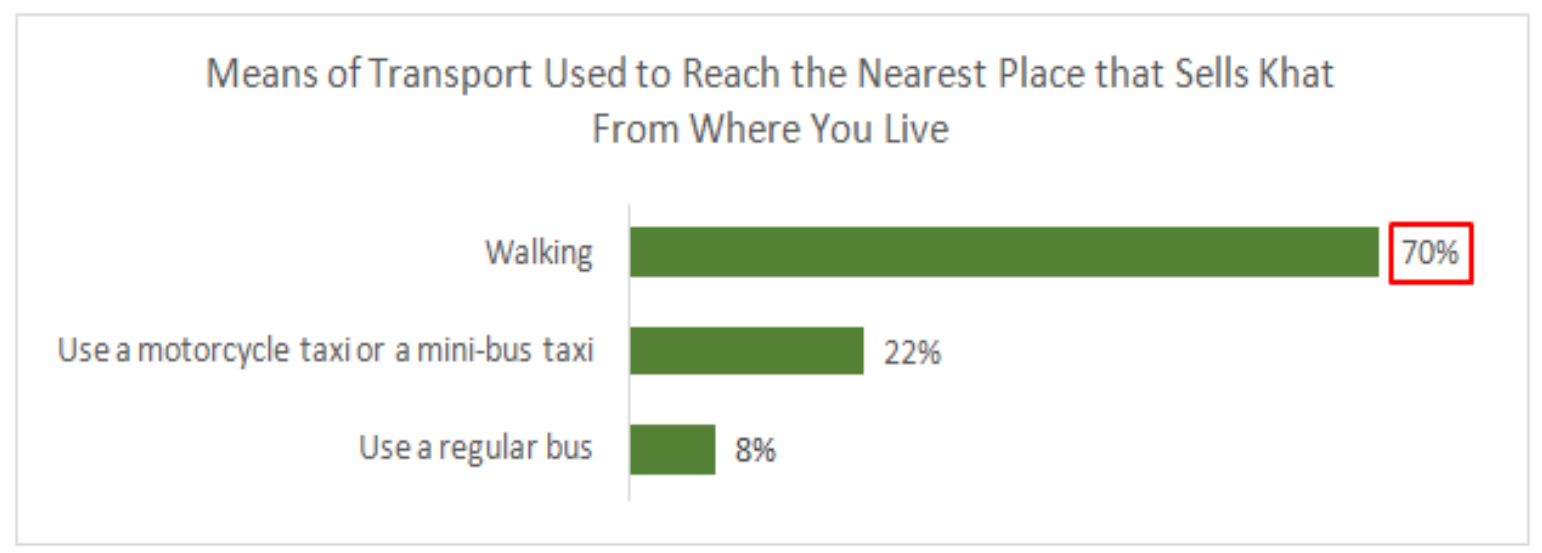

\section{Health and socio-economic impacts of khat chewing}

When khat users were asked to provide the perceived benefits of taking Khat, the majority cited excitement and a feeling of well-being ( $46 \%$ and $41 \%$, respectively; see Figure 17). In essence, virtually all the perceived benefits relate to peer-group pressure and dealing with boredom rather than any positive socio-economic or health benefits. Further, the perceived benefits such as increased alertness, dealing with stress, etc. are the result of psychotropic substances that have many harmful effects.

Figure 17. Benefits of taking khat.

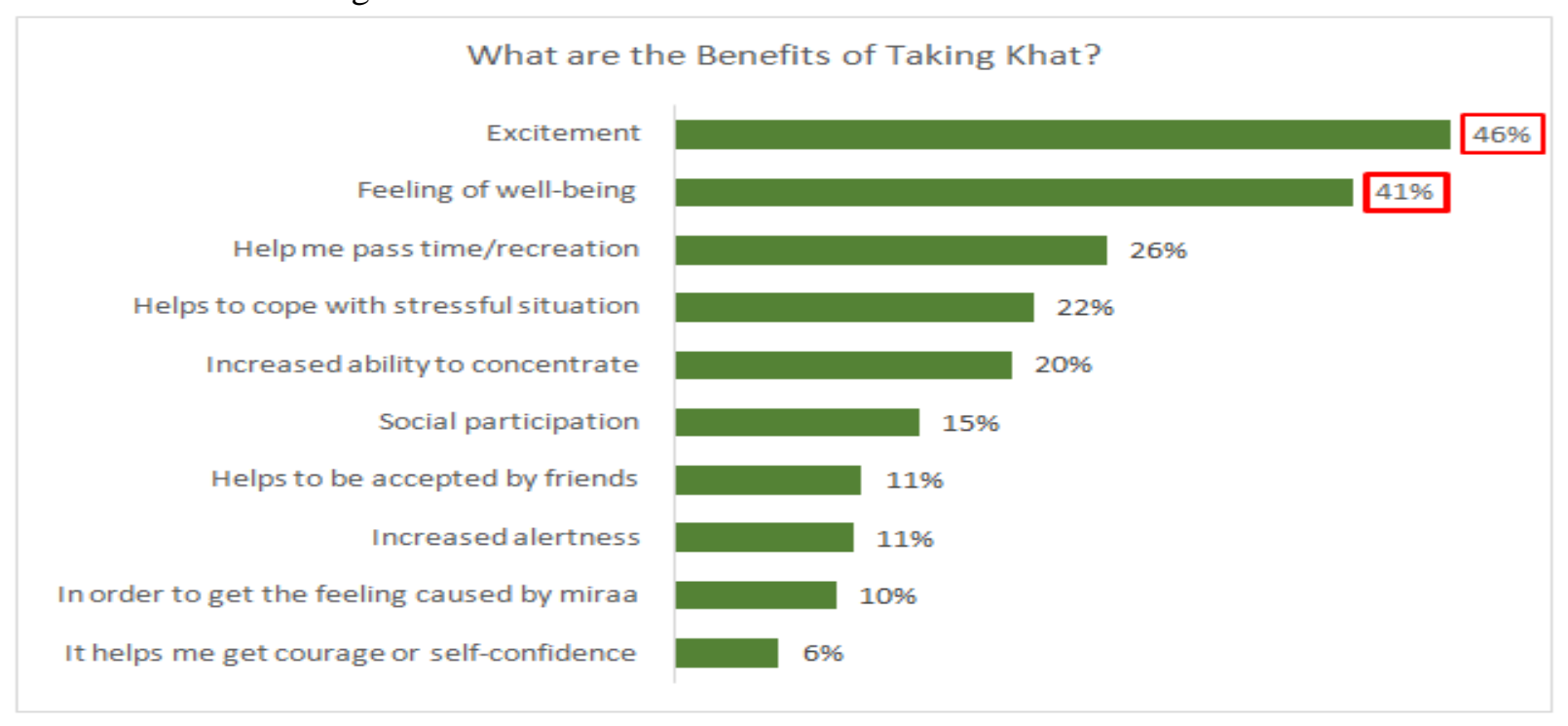


These negative effects of khat have wide-reaching effects on the individual and the community, e.g. poor performance at work and poor health. One of the major negative effects of chewing khat was reported to be sleeping disorders $(83 \%)$, followed by reduced appetite $(50 \%)$. Other effects mentioned included depression and anxiety ( $29 \%$ and $24 \%$, respectively) (see Figure 18 ).

Figure 18. Negative effects of chewing khat.

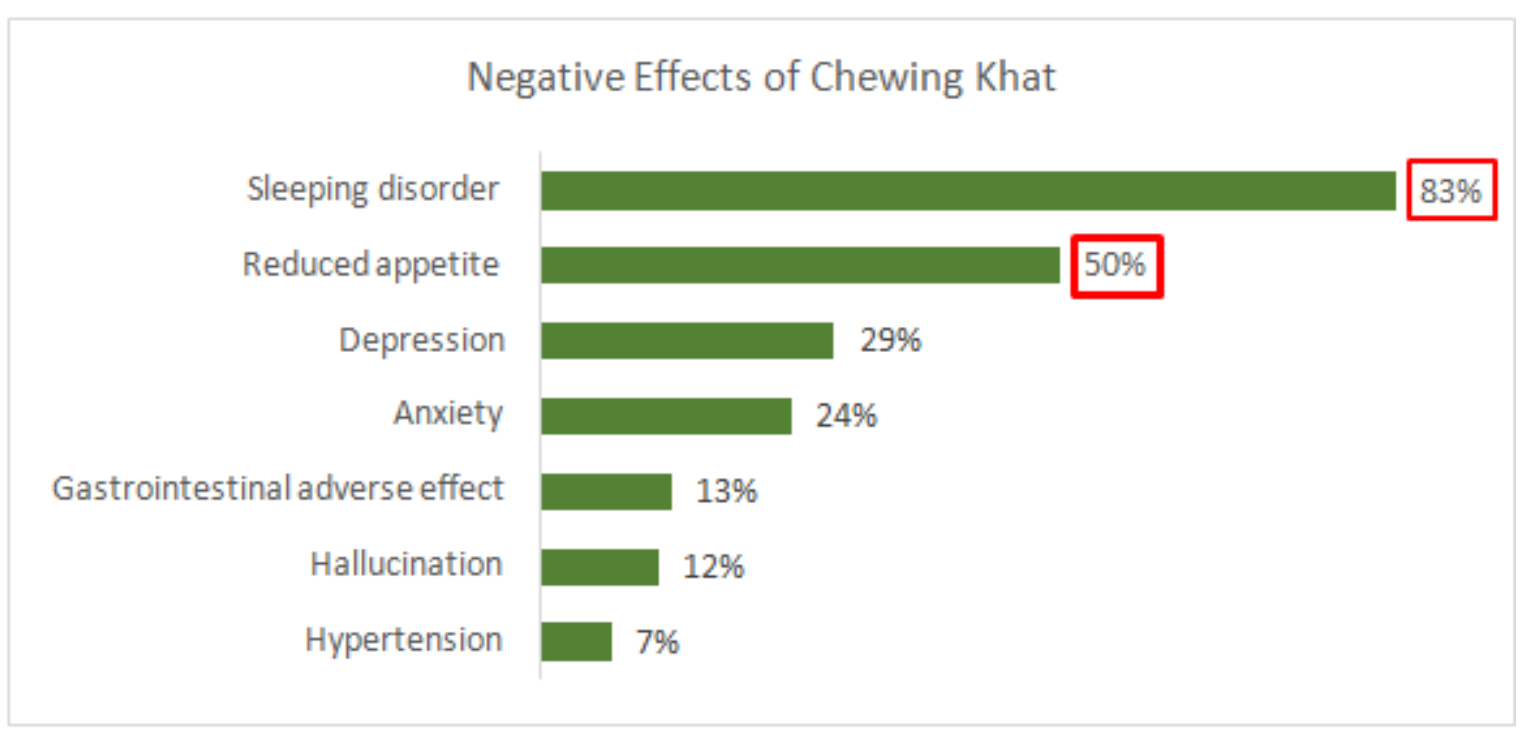

It is almost impossible for the user to be productive in nay environment if deprived of sleep. Reduced appetite leads to feeling less energized, because the body requires food to operate consistently well. Depression and anxiety clearly also have serious detrimental effects for the individual and the community. From the results, it is clear that khat usage has a significant social impact, reducing meaningful interaction between khat users and other members of society (see Figure 19). A total of 54\% of respondents reported relationship problems with friends and neighbors and $47 \%$ reported relationship problems within their families. Although it is acknowledged that khat use has negative socio-economic consequences, the data from this study clarify the main impacts on khat users, including regular criminal activity (11\%), lower productivity at work (30\%), and absenteeism from work (18\%). These factors lead to social problems for individuals but all these problems also have negative effects on other people who do not use khat.

Figure 19. Social effects of chewingkhat.

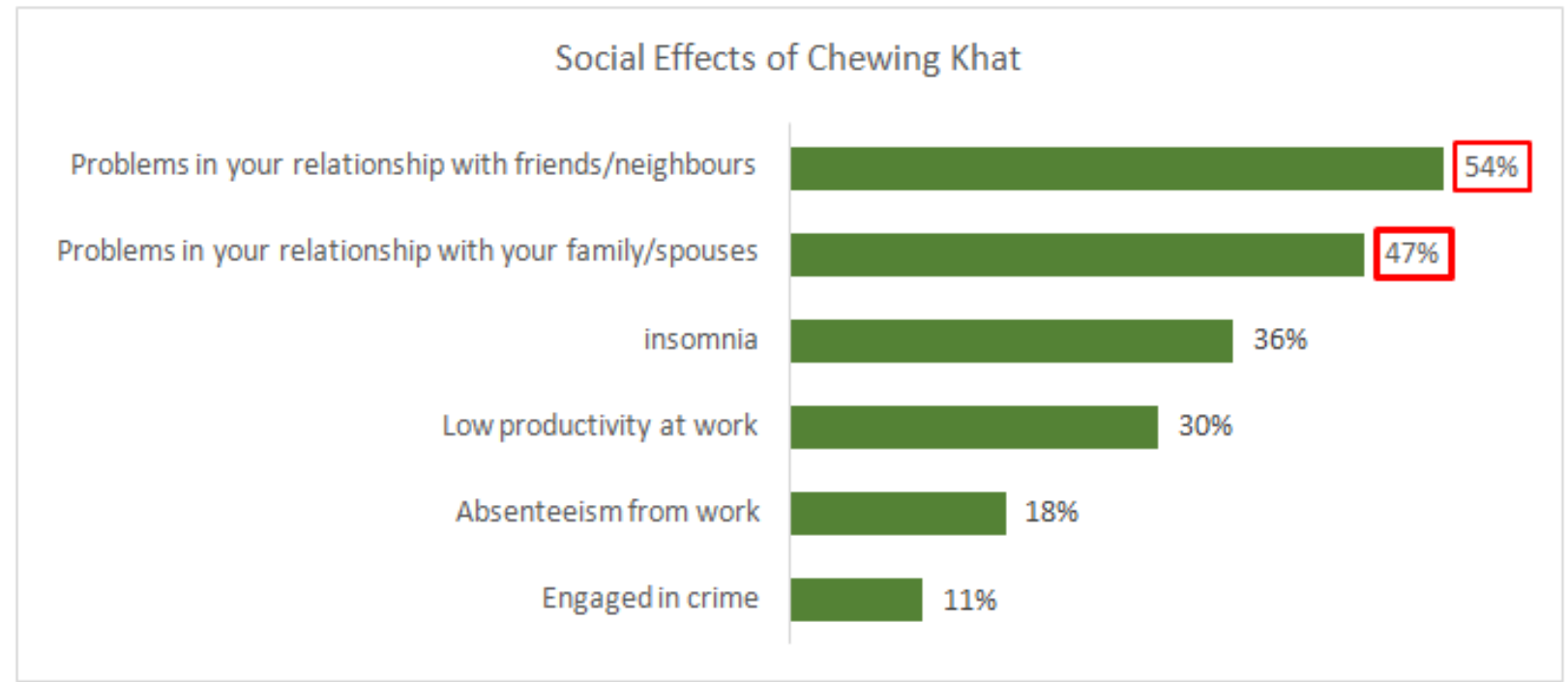

Figure 20 reveals that $92 \%$ of respondents had tried to stop chewing khat, due to negative health effects $(61 \%)$, the cost in terms of time (52\%) and money (44\%), and negative effects on work (33\%). This shows that, with effective intervention and proper methods of community engagement and education, reducing khat usage can be achieved, as discussed in more details later. 
Figure 2.Numbers attempting to quit khat chewing andreasons for this decision.
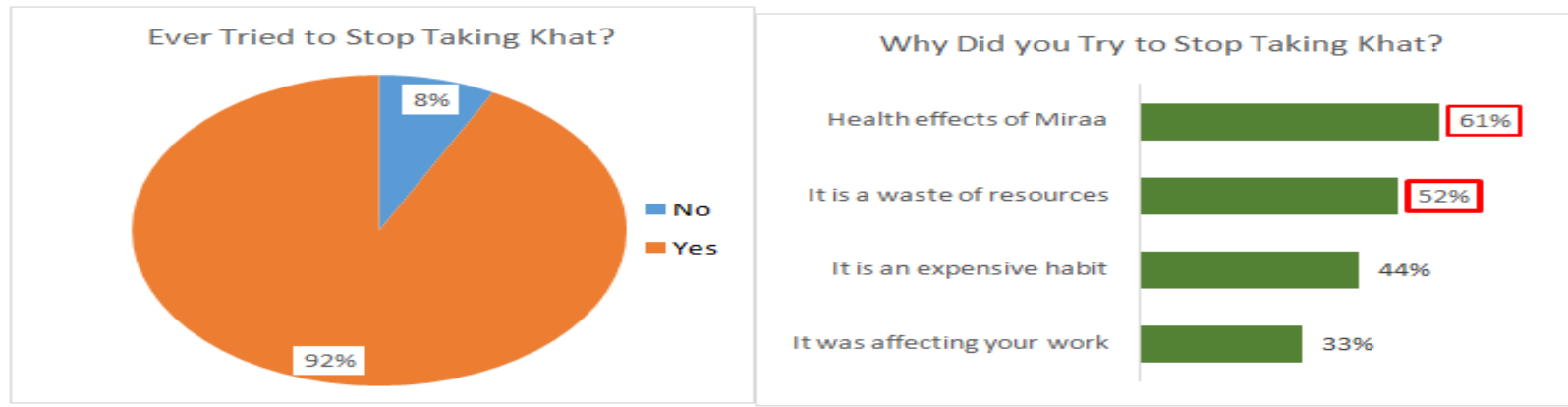

Regarding additive substances used when chewing khat, the majority of respondents reported drinking tea (78\%) and smoking cigarettes (57\%) (see Figure 21). Knowledge of these additive substances is important for developing strategies to break users' habits and, ultimately, reduce khat usage, as will be discussed later.

Figure 21. Additive substance used to chew khat.

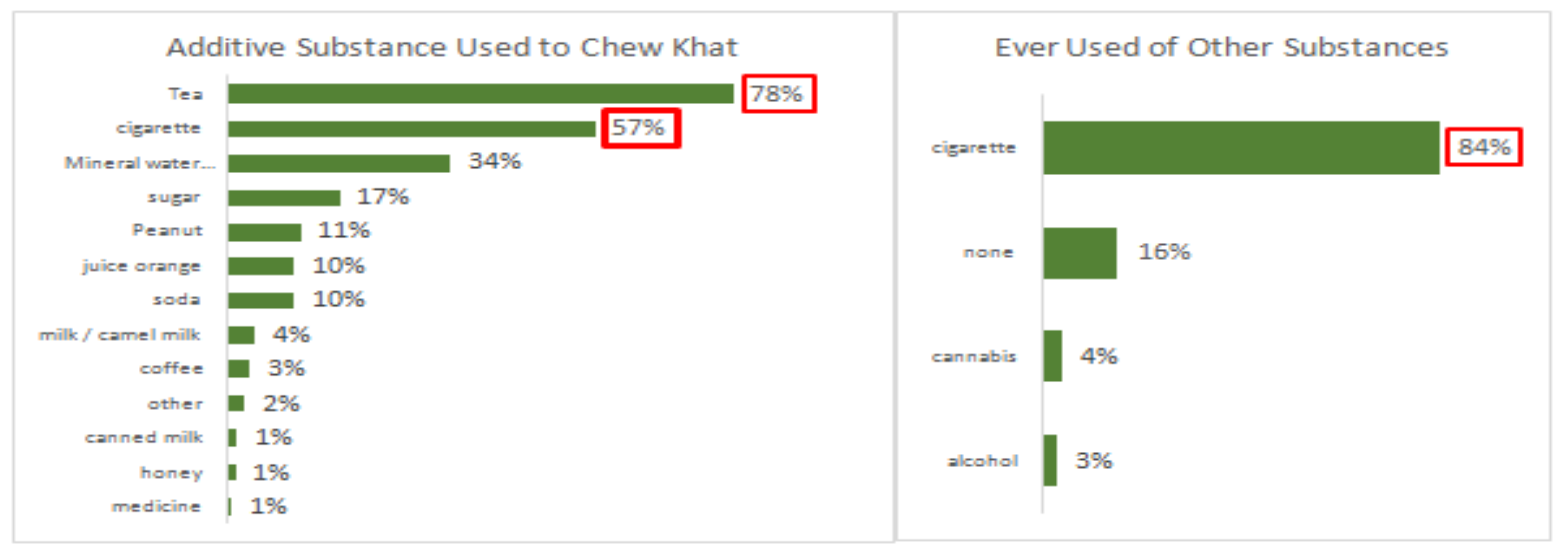

Khat intake per day by respondents was found to be high (Figure 22), with the average per day being over $250 \mathrm{~g}$. More than half of the respondents $(60 \%)$ chewed $250 \mathrm{~g}, 16 \%$ chewed $120 \mathrm{~g}, 19 \%$ chewed $500 \mathrm{~g}$, and $5 \%$ chewed $1 \mathrm{~kg}$. The cost to users for this high usage is shown in Table II: respondents spent an average of USD 7.29 per day on khat, with a maximum amount of USD 45and a minimum amount of USD 0.50. From the sample of 383 khat users interviewed, it was observed that the entire sample spent a total of USD 2,792.07 per day on khat. There can be no argument that this money could be put to better use, e.g. paying school fees, buying food, farm improvements, and buying clothes.

Figure22. Quantity of khat chewed per day.

\section{Quantity of Khat Chewed per Day}

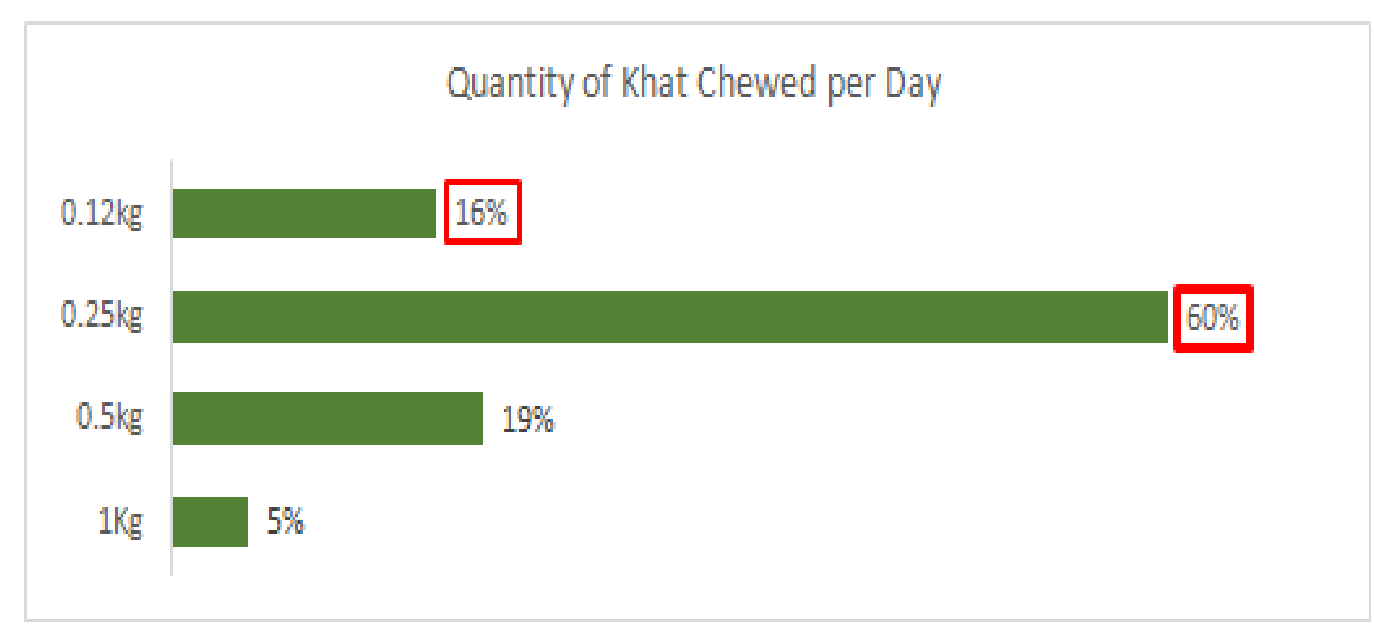

Table II. Money spent on khat per day (USD). 


\begin{tabular}{cc}
\hline Money Spent on Khat per Day (USD) & \\
\hline Mean & 7.29 \\
Max & 45.00 \\
Min & 0.50 \\
Median & 5.00 \\
\hline
\end{tabular}

\section{Discussion of findings}

A total of 383 face-to-face interviews were administered to males aged 18 and above from five districts in Mogadishu (Hodan, Wadajir, Hamarweyne, Hawlwadaag, and Waabari), the capital city of Somalia. The study population was estimated to be 120,000 individuals (4\% of the population of Mogadishu).The salient demographic information was gathered, along with details covering all aspects of khat usage. Notably, most of the respondents are married $(76 \%)$.

The average level of education of khat users was found to be low: only $1 \%$ had attended university; and only $13 \%$ had received secondary-school education. Notably, the figure of $12 \%$ for those who had received no formal education is very high in a Somalian context.

A few respondents (24\%) reported that they had persons in their household under 18 years of age not attending school, mainly due to lack of school fees (91\%) and lack of a school uniform (36\%). These are, I believe, issues that can be addressed through help from NGOs and charitable organizations in Somalia. Somalia has been associated with violence over recent years, but it seems a threat to personal security is not a significant factor in school attendance (only $4 \%$ mentioned security as a reason for not attending school), contrary to what many may have believed. There is need, therefore, to increase awareness among, and influence, khat users regarding attending higher-level schooling, which could reduce khat consumption. A total of $40 \%$ of the respondents earned their income through unskilled domestic labor work and $22 \%$ from "handicrafts" jobs, with less than $10 \%$ working in white-collar jobs. This shows that if the khat usage can be, reduced and if there can be continuation into higher education, then there can be socio-economic benefits. In terms of economic benefits $(51 \%$ of respondents earned USD 150 to 250, 24\% earned over USD 250, and 24\% earned less than USD 150), if the time and money khat users spent chewing khat could be fully and positively utilized, then the monthly disposable personal (and family) income would increase significantly, with inherent benefits to society as a whole.

Initiation into the Khat chewing comes from three main areas: close friends (67\%); own initiation (28\%); and family members (4\%). Peer pressure clearly plays a key role in khat-usage initiation and most peer groups are formed as a result of idleness/ lack of other engaging activities and opportunities. Encouraging such activities and opportunities could, therefore, lead to a decrease in khat usage. Half of the family members in households of interviewed khat users also used khat. This insight is very worrying as it shows how whole families can be affected, further demonstrating the need to reduce or eradicate hat use, especially as since we know that khat usage in Somalia is generally very high. Khat usage in the five surveyed districts of Somalia was also shown to be long-term behavior: $94 \%$ of respondents reported using khat for more than three years. As the detrimental effects of khat usage are long-term, this further emphasizes the need to reduce or eradicate khat use. The majority of the respondents reported that they started taking khat for excitement (44\%), for a feeling of well-being (39\%), and to help pass the time $(31 \%)$. Only $1 \%$ of khat users reported that they do it because it is part of their culture, contrary to what may have been expected. Khat was mainly chewed by respondents on a daily basis (54\%), with $98 \%$ of khat users consuming it weekly and $90 \%$ consuming hat more than once in a week. In other words, the addiction rate is high. Significantly, the majority chewed khat in the afternoon and evening (92\%). Therefore, engagement processes, campaigns, and activities should mainly be focused on the afternoon to evening times. Khat market bays and street khat vendors were the main sellers of the khat. Although selling khat is a business that generates income, to reduce khat consumption, there is need to pursue the khat sellers and encourage or incentivize them to sell useful or healthy goods.

Training programs could also be initiated to help them other businesses that will generate income, e.g. barbers, saloons, etc. 
As we have seen, the negative effects of Khat on the individual (sleeping disorders $(83 \%)$, reduced appetite (50\%), depression (29\%), and anxiety (24\%)) have wide-reaching effects on the whole community. this highlights the fact that the issue of khat consumption in the five Somalia districts studied is a very serious issue that needs quick and well-planned intervention. Khat users experienced problems in their relationships with their friends, neighbors, and family/spouses. During the intervention process, it would, therefore, be advisable to involve members of the household who do not consume khat to helps the users understand the consequences of its use, possibly through listening to or watching educational programs from radio and television, discussing it together, and providing assistance to all parties through the process of stopping, including society activities, learning, playing, and working together.

Notably, $92 \%$ of respondents had tried (and failed) to stop chewing khat. This extremely high number shows that, with effective help to quit (proper community engagement in different productive activities and social education on the harmful effects khat usage), the negative social effects of khat usage can be drastically reduced. The vast majority would welcome and support the effort to get them stop chewing khat. The major reason they tried to stop chewing Khat was the negative health effects. One cannot plan to achieve anything before first having a healthy community or household, because health is paramount for all human beings.

To demonstrate the willingness of many users to stop (and be helped to stop) using khat, while also highlighting some of the difficulties in breaking the cycle, the following quotes from the interviews are provided:

- "I used the Khat as part of my daily life. I believe that I can't work properly without chewing Khat."

- "I was addicted this Khat so much that I can't even think that I can live without it."

- "I am surrounded a lot of friends who use Khat, therefore even if I am going to buy it they give me some of their Khat".

Notably, most khat users were also heavy users of cigarettes (and, often, the consumption was linked). The same strategies for reducing the consumption of khat should be used at the same time to reduce and eradicate use of cigarettes. Often you may have to achieve reduction and eradication of these two addictive habits for you to succeed in breaking the khat habit. Leaving one behind is like treating the symptoms while the disease is still not cured. Therefore, targeting the both khat and cigarettes in the strategies for community engagement and community education will likely be more effective. The community should be encouraged to take breakfast with something other than khat, e.g. sweet potatoes, bread, arrow roots, bananas, etc. They should be encouraged to take things like tea, water, milk, soda, juice, etc. after lunch, supper, or any other meal to help break the association between these beverages and the consumption of khat.

On average Khat chewing per day per consumer is over $250 \mathrm{~g}$. The respondents spent an average of USD 7.29 daily on purchasing Khat (a total for all 383 respondents of USD 2,747 per day). The money used for khat purchase could be spent instead on, for example, paying school fees, buying food items, farm improvements, and buying clothes, among many other beneficial activities in the community. Finally, it is worth noting that there may, however, be uses for khat that do have socio-economic benefits. Khat could potentially be can be used, if approved by the medical body in Somalia, to make medicines that can be of help to the community and even be exported to other countries, once tested and approved. Herbal medicine is still a preference for the majority of people in many places, and this opportunity should not be overlooked.

\section{Conclusion and Policy Recommendations}

Based on the results of the study, as well as the review of the literature, I provide several possible strategies and techniques that can used to prevent and stop the chewing of khat, including tackling the trading of khat:

- Create more opportunities for employment that will engage employees for most of their day time, from morning to evening. This could be achieved through government initiatives, NGOS, or the private sector, among others.

- Create more learning programs and opportunities for all age groups (we have seen that even the older generation uses khat).

- Hostintra- and inter-community competitions (e.g. football, volleyball, netball, handball, table tennis, rugby, basketball, among others).

- Increase farming through irrigation for crops such as bananas, flowers, etc., i.e. cropsthat can flourish in Somalia's topography and climate. 
- Engage with member of communities, especially the men, at a very early age, before they begin using khat.

Finally, it must be noted that ease of access to these programs, events, and jobs is key. We all know and understand that "out of sight is out of mind."Our study revealed that khat bundles, vendors, and even the khat markets are extremely close for the majority of respondents $(62 \%$ reported the distance to be $0.5 \mathrm{~km}$ or less and $71 \%$ of users needed 15 or less minutes to reach the khat vendors, with $70 \%$ travelling by foot). The programs and measures put in place must be equally, if not more, accessible. The best way to succeed in occupying people's idle time is to make sure that you bring the above-mentioned interventions closer to the communities that need them.

\section{References}

Aden, A., Dimba, E. A. O., Ndolo, U. M., \& Chindia, M. L. (2006). Socio-economic effects of khat chewing in north eastern Kenya. East African Medical Journal, 83(3), 69.

Anderson, D., \& Carrier, N. C. (2011). Khat: social harms and legislation: a literature review. Home Office.

Genene, B., Haniko, N., \& Weldegerima, B. (2009). Prevalence, factors and consequences of Khat chewing among high school students of Gondar town, Northwestern Ethiopia. Pharmacol online, 3, 387-97.

Hansen, P. (2010). The ambiguity of khat in Somaliland. Journal of ethnopharmacology, 132(3), 590-599.

Kassim, S., Croucher, R., \& Al'Absi, M. (2013). Khat dependence syndrome: a cross sectional preliminary evaluation amongst UK-resident Yemeni khat chewers. Journal of ethnopharmacology, 146(3), 835-841.

Megerssa, B., Esayas, A., \& Mohamed, A. (2014). Socio-Economic Impact of Khat in Mana District, Jimma Zone, South Western Ethiopia. Discourse journal of agriculture and food sciences, 2(2), 21-32.

Nabuzoka, D., \& Badhadhe, F. A. (2000). Use and perceptions of khat among young Somalis in a UK city. Addiction Research, 8(1), 5-26.

Pantelis, C., Hindler, C. G., \& Taylor, J. C. (1989). Use and abuse of khat (Catha edulis): a review of the distribution, pharmacology, side effects and a description of psychosis attributed to khat chewing. Psychological medicine, 19(3), 657-668.

Sheikh, K. A., El-setouhy, M., Yagoub, U., Alsanosy, R., \& Ahmed, Z. (2014). Khat chewing and health related quality of life: cross-sectional study in Jazan region, Kingdom of Saudi Arabia. Health and quality of life outcomes, 12(1), 1. 